\title{
ĐÁNH GIÁ HIÊ̂U QUẢ ĐIỀU TRI HộI CHỨNG CỔ-VAI-TAY DO THOÁI HÓA ĐỐT SỐNG CỔ BẰNG PHƯƠNG PHÁP ĐIÊ̂N CHÂM KẾT HỢP XOA BÓP BẤM HUYỆT
}

\section{TÓM TĂT}

Mục tiêu: (1) Đánh giá hiệu quả điều trị bệnh nhân có hối chứng cổ - vai - tay do Thoái hóa đốt sống cổ bằng phương pháp điện châm kết hợp xoa bóp; (2) Xác định một số yếu tố liên quan đến kết quả điểu trị ở bệnh nhân có hội chứng cổ - vai - tay do thoái hóa đốt sống. Đối tượng và phương pháp nghiên cứu: Phương pháp tiến cứu, thử nghiêm lâm sàng mở, so sánh trước và sau điêu trị được tiến hành trên 30 bênh nhân hội chứng cổ - vai - tay do thoái hóa đốt sổng cổ. Kết quả: Sau 14 ngày điêu trị đã cải thiện rõ rêt các triêu chứng lâm sàng của bểnh với $73,33 \%$ xếp loại tốt, $20 \%$ xếp loại khá, $6,67 \%$ xếp loại kém. Kết luân: Điện châm kết hợp xoa bóp bấm huyệt có tác dụng giảm đau và phục hồi chức năng vận động các khớp cổ - vai - tay trên bệnh nhân có thoái hóa đốt sống cổ. Bệnh nhân < 50 tuổi cho kết quả điều trị tốt hơn so với nhóm bệnh nhân $\geq 50$ tuổi $(p<0,05)$; Thời gian mắc bệnh $\leq 3$ tháng cho kết quả điêu trị tốt hơn những bệnh nhân mắc bệnh $>3$ tháng.

Tư khóa: hội chứng cổ vai tay, điện châm.

\section{SUMMARY}

\section{EVALUATING THE EFFECTIVENESS OF TREATMENT OF PATIENTS WITH NECK - SHOUDER - ARM SYNDROME DUE TO CERVICAL SPINE DEGENERATION BY ELECTRO-ACUPUNTURE AND ACUPRESSURE MASSAGE}

Objectives: (1) To evaluate the effectiveness of treatment of patients with neck - shoulder - arm syndrome due to spine degeneration by electroacupuncture and acupressure massage; (2) Identify some factors related to treatment outcomes in patients with neck - shoulder - arm syndrome caused by cervical vertebra degeneration. Subjects and research methods: Research method, open clinical trial, comparing before and after treatment were conducted on 30 patients with neck - shoulder - arm syndrome caused by degenerative cervical vertebrae. Results: After 14 days of treatment, the clinical symptoms of the disease have been significantly improved with $73.33 \%$ rated good, $20 \%$ rated good, $6.67 \%$ rated poor. Conclusion: Electric acupuncture combined with acupressure massage has the effect of relieving pain and restoring motor function of neck shoulder - arm joints in patients with cervical

1Trường Đại học Y khoa Vinh

Chịu trách nhiệm chính: Nguyễn Văn Tuấn

Email: tuanminh1975@gmail.com

Ngày nhận bài: 18.01.2021

Ngày phản biên khoa học: 8.3.2021

Ngày duyệt bài: 19.3.2021

\section{Nguyễn Văn Tuấn ${ }^{1}$, Trần Thị Yến ${ }^{1}$}

degeneration. Patients $<50$ years old give better treatment results than patients $\geq 50$ years old $(p<0,05)$. Duration of illness: $\leq$ 3months, the treatment results are better than patients with disease> 3 months.

Key words: hand shoulder syndrome, electric acupuncture

\section{I.ĐẶT VẤN ĐỀ}

Hội chứng cổ - vai - tay là một bệnh lý khá phổ biến trong lâm sàng các bệnh về nội khoa, không phân biệt tuổi, giới tính, tâng lớp xã hội và nghề nghiệp lao động nặng hay nhẹ. Bệnh có thể khởi phát đột ngột hoặc từ từ, nguyên nhân thường gặp do thoái hóa đốt sống cổ. Bệnh tuy không nguy hiểm nhưng thường kéo dài, gây đau đớn và hạn chế vận động, ảnh hưởng tới sức khỏe, khả năng lao động của người bệnh [1].

Hội chứng cổ - vai - tay với các triệu chứng chính là đau cổ gáy lan ra vai tay kèm theo một số rối loạn cảm giác hoặc vận động tại vùng chi phối của rễ dây thân kinh cột sống cổ bị ảnh hưởng. Để điêu trị chứng bệnh này, y học hiện đại cũng như y học cổ truyên có rất nhiếu phương pháp khác nhau. Các phương pháp dùng thuốc là điêu trị thuốc giảm đau, phong bế thân kinh, phẫu thuật có nhiều tác dụng phụ và giá thành cao. Tai Việt Nam phương pháp không dùng thuốc là châm cứu, xoa bóp bấm huyệt, phục hồi chức năng có tác dụng giảm đau nhanh và an toàn.[2].

Y học cổ truyên mô tả chứng bệnh này trong phạm vi chứng tý, nguyên nhân do phong hàn , thẩp tà xâm nhập vào cơ thể nhân khi chính khí hư suy, khiến cho khí huyết vận hành không thông gây đau gọi là " chứng tý". Để góp phân vào nghiên cứu điều trị hội chứng cổ - vai - tay chúng tôi tiến hành nghiên cứu đề tài: "Đánh giá hiêu quả điều trị hôi chứng cổ- vai- tay do Thoái hóa đốt sống cổ bằng phương pháp điện châm kết hợp xoa bóp bấm huyệt tại Phòng khám Trường Đại Học Y khoa Vinh năm 2017" với hai mục tiêu sau:

1. Đánh giá hiệu quả điều trị bênh nhân có hội chứng cổ - vai - tay do Thoái hóa đốt sông cổ bằng phương pháp điện châm và xoa bóp.

2. Xác định một số yếu tố liên quan đến kêt quả điều trị ở bệnh nhân có hội chứng cổ - vai tay do thoái hóa đốt sông cô. 


\section{II. ĐỐI TƯợNG VÀ PHƯƠNG PHÁP NGHIÊN CỨU \\ 2.1. Đối tượng nghiên cứu}

2.1.1. Tiêu chuấn chọn bệnh nhân:

- Bệnh nhân $\geq 30$ tuổi.

- Được chẩn đoán hội chứng cổ - vai - tay do THĐSC đến điều trị tại Bệnh viện Trường Đại học Y khoa Vinh.

- Bệnh nhân không kèm theo các bệnh mạn tính.

- Bệnh nhân tự nguyện tham gia nghiên cứu và tuân thủ đúng quy trình điều trị.

\subsubsection{Tiêu chuân loại trừ bệnh nhân:}

- Các bệnh không thuộc thể phòng hàn thấp của YHCT

- Bệnh nhân dùng thêm các phương pháp điều trị khác.

- Bệnh nhân không tuân thủ, không hợp tác theo quy trình điều trị.

\subsection{Phương pháp nghiên cứu}

\subsubsection{Thiêt kếnghiên cứu.}

Nghiên cứu theo phương pháp thử nghiệm lâm sàng, so sánh trước và sau điều trị.

\subsubsection{Cỡ mẫu, chon mẫu nghiên cứu.}

Chọn mẫu thuận tiện có chủ đích 30 bệnh nhân có đủ tiêu chuẩn đưua vào nghiên cứu.

2.2.3.Phương pháp tiến hành nghiên cứu.

- Khám và chọn bệnh nhân theo tiêu chuẩn nghiên cứu.

- Điều trị điện châm: chọn công thức huyệt điều trị theo quy trình kỹ thuật châm cứu của bộ Y tế về điều trị Hội chứng -vai- tay. Quy trình 46

\begin{tabular}{|c|c|c|}
\hline Giáp tích C4- C7 & Phong trì & Thiên trụ \\
\hline Đại chùy & Kiên tỉnh & Kiên ngung \\
\hline Kiên trinh & Khúc trì & Chi câu \\
\hline Hợp cốc & Cao hoang & Thiên tông \\
\hline Ngoại quan & Hậu khê & Tiểu hải \\
\hline A thị huyệt & Lạc chẩm & Kiên trung du \\
\hline
\end{tabular}

Thời gian kích thích điện khoảng 20-30 phút và ngày một lần.

- Điều trị xoa bóp bấm huyệt: Lần lượt thực hiện các động tác của phương pháp XBBH bao gồm: Động tác xoa, xát, day, ẩn, bấm, rung, vận động các khớp đốt sống cổ

\subsubsection{Chỉ tiêu quan sát}

- Phân bố theo nhóm tuổi. phân bố theo giới tính, nghề nghiệp và thời gian bị bệnh.
- Theo dõi các chỉ tiêu lâm sàng, trước và sau đợt điều trị: mức độ đau của bệnh nhân, đo tầm vận động CSC.

- Đánh giá hiệu quả điều trị chung.

- Một số yếu tố liên quan kết quả điều trị.

2.2.5.Phương pháp đánh giá kết quả điều trị hội chứng cổ - vai - tay

- Đánh giá mức độ đau theo thang điểm VAS ở thời điểm sau 7 ngày và sau 14 ngày điều trị.

Phân loại mức độ đau như sau: Mức $0-1$ điểm: Không đau; Mức $2-4$ điểm: Đau ít; Mức 5 - 6 điểm: Đau vừa; Mức $7-8$ điểm: Đau nhiề; Mức $9-10$ điểm: Rất đau.

- Tầm vận động cột sống cổ:

Tốt: Nếu góc vận động cúi, ngửa cổ lớn hơn 300 Nghiêng phải, trái, xoay sang trái, phải: $40^{\circ}$; Khá: Nếu góc vận động cúi, ngửa cố từ 20 độ $<300$ Nghiêng phải, trái, xoay sang trái, phải: 250 - 390; Kém: Nếu góc vận động cúi, ngửa dưới 200 Nghiêng phải, trái, xoay sang trái, phải dưới 250

- Kết quả chung: Căn cứ mức độ đau, tầm vận động cột sống cổ, trước và sau điêu trị chia làm ba mức độ:

\begin{tabular}{|c|c|c|c|}
\hline Phân loại & Mức độ đau & Vận động CSC & Đáp ứng \\
\hline Tốt & Không đau & Mức độ tốt & $\begin{array}{c}\text { Đáp uúng } \\
\text { tốt }\end{array}$ \\
\hline Khá & $\begin{array}{c}\text { Đau vữa hoặc } \\
\text { nhẹ }\end{array}$ & Mức độ khá & $\begin{array}{c}\text { Đáp ứng } \\
\text { khá }\end{array}$ \\
\hline Kém & $\begin{array}{c}\text { Đau nhiều } \\
\text { hoặc rất đau }\end{array}$ & Mức độ kém & $\begin{array}{c}\text { Đáp ứng } \\
\text { kém }\end{array}$ \\
\hline
\end{tabular}

2.2.6. Xử lý số liệu

Các số liệu nghiên cứu được xử lý bằng phần mềm SPSS 20.0

\section{KẾT QUẢ NGHIÊN CỨU}

\section{1. Đặc điểm chung của bệnh nhân} nghiên cứu

- Giới tính: Nam 9/30 bệnh nhân (30\%); Nữ: 21/30 bệnh nhân (70\%).

- Tuổi: Có 21/60 bệnh nhân hôi chứng cổ vai - tay do thoái hóa đốt sống cổ ở độ tuổi từ 40 đến 60 (chiếm 70\%).

- Nghề nghiệp: Tỷ lệ bệnh nhân lao động trí óc là 26,67\%, tỷ lệ bệnh nhân lao động chân tay $60 \%$, tỷ lệ bệnh nhân lao động khác 13,33\%.

\section{2. Đánh giá kết quả điêuu trị}

Bảng 1. Mức độ đau theo cảm giác chủ quan (theo thang điểm VAS)

\begin{tabular}{|c|c|c|c|c|c|c|c|}
\hline \multirow{2}{*}{$\begin{array}{l}\text { Thang điểm } \\
\text { VAS(điểm) }\end{array}$} & \multicolumn{2}{|c|}{ Trước điêuu trị } & \multicolumn{2}{|c|}{ Sau điều trị 7 ngày } & \multicolumn{2}{|c|}{ Sau điêuu trị 14 ngày } & \multirow[b]{2}{*}{ p } \\
\hline & $\mathbf{N}=\mathbf{3 0}$ & Tỷ lệ(\%) & $\mathbf{N}=\mathbf{3 0}$ & Tỷ lệ (\%) & $\mathbf{N}=\mathbf{3 0}$ & Tỷ lệ (\%) & \\
\hline $0-1$ & 0 & 0 & 15 & 50 & 26 & 86,67 & \\
\hline $2-4$ & 5 & 16,67 & 3 & 6,67 & 0 & 0 & $<0,05$ \\
\hline $5-6$ & 15 & 50 & 9 & 23,33 & 3 & 10 & \\
\hline $7-8$ & 8 & 26,67 & 5 & 16,67 & 1 & 3,33 & \\
\hline
\end{tabular}


VIETNAM MEDICAL JOURNAL N01 - APRIL - 2021

\begin{tabular}{|c|c|c|c|c|c|c|c|}
\hline $9-10$ & 2 & 6,66 & 1 & 3,33 & 0 & 0 & \\
\hline Tống & $\mathbf{3 0}$ & $\mathbf{1 0 0}$ & $\mathbf{3 0}$ & $\mathbf{1 0 0}$ & $\mathbf{3 0}$ & $\mathbf{1 0 0}$ & \\
\hline
\end{tabular}

Sau 14 ngày điều trị bệnh nhân không đau chiếm $86,67 \%$, có $0 \%$ số bệnh nhân đau ít và $10 \%$ số bệnh nhân đau vừa và 3,33\% số bệnh nhân đau nhiêu, không còn số bệnh nhân rất đau. Sự khác biệt có ý nghĩa thống kê $p<0,05$.

Bảng 2. Sự cải thiện tâm vận động cột sống cổ

\begin{tabular}{|c|c|c|c|c|c|c|c|}
\hline \multicolumn{2}{|c|}{ Vận động cột sống cổ } & \multicolumn{2}{|c|}{ TÐT } & \multicolumn{2}{|c|}{ SפT } & \multirow{2}{*}{$\begin{array}{c}\text { Xếp loại } \\
\text { Tốt }\end{array}$} & \multirow{2}{*}{$\begin{array}{c}\mathbf{P} \\
<0,05\end{array}$} \\
\hline \multirow{3}{*}{ Cúi ngửa } & $>300$ & 17 & 56,67 & 26 & 86,67 & & \\
\hline & $20-300$ & 10 & 33,33 & 3 & 10 & Khá & $<0,05$ \\
\hline & & 3 & 1 & 1 & 3,33 & Kém & $<0,05$ \\
\hline \multirow{3}{*}{$\begin{array}{l}\text { Nghiêng xoay đối } \\
\text { diện bên đau }\end{array}$} & $>400$ & 22 & 73,34 & 29 & 96,67 & Tốt & $<0,05$ \\
\hline & $25-390$ & 7 & 23,33 & 1 & 3,33 & Khá & $<0,05$ \\
\hline & 250 & 1 & 3,33 & 0 & 0 & Kém & $<0,05$ \\
\hline
\end{tabular}

Trước điều trị, 17 bệnh nhân (56,67\%) vận động tư thế cúi ngửa tốt sau điều trị lên tới 26 bệnh nhân $(86,67 \%)$. Loại khá trước điều trị chiếm $33,33 \%$ sau còn $10 \%$. Loại kém trước điều trị chiếm $10 \%$ sau là 3,33\%. Sự khác biệt có ý nghĩa thống kê $\mathrm{p}<0,05$. Ở tư thế nghiêng xoay đối diện bển đau, loại tốt từ 22 bệnh nhân chiếm $73,34 \%$ sau điêu trị tới 29 bệnh nhân chiếm $96,67 \%$, loại khá trước điều trị chiếm $23,33 \%$ sau còn $3,33 \%$, loại kém khồng còn bệnh nhân nào, có ý nghĩa thổng kê $\mathrm{p}<0,05$.

Bảng 4. Tuổi bị bệnh

Bảng 3. Kết quả chung đợt điều trị

\begin{tabular}{|c|c|c|}
\hline \multirow{2}{*}{ Mức độ } & \multicolumn{2}{c|}{ Nhóm nóm nhiên cứu } \\
\cline { 2 - 3 } & Số bệnh nhân & Tỷ lệ (\%) \\
\hline Tốt & 22 & 73,33 \\
\hline Khá & 6 & 20 \\
\hline Kém & 2 & 6,67 \\
\hline Tống & $\mathbf{3 0}$ & $\mathbf{1 0 0}$ \\
\hline
\end{tabular}

Sau đợt điều trị ta thấy mức đô khá và tốt chiếm tỷ lệ lần lượt là73,33\% và 20\%. Mức độ kém chiếm tỷ lê là $6,67 \%$.

3.3. Một số yếu tố liên quan đến kết quả điều trị

\begin{tabular}{|c|c|c|c|c|c|c|c|c|c|}
\hline Kết quả & & Kém & & Khá & & Tốt & & Tống & \\
\hline uổi & $\mathbf{n}$ & Tỷ lệ (\%) & $\mathbf{n}$ & Tỷ lệ (\%) & $\mathbf{n}$ & Tỷ lệ (\%) & n & Tỷ lệ (\%) & $\mathbf{P}$ \\
\hline$<50$ & 0 & 0 & 2 & 6,67 & 14 & 46,67 & 16 & 53,33 & \\
\hline$\geq 50$ & 2 & 6,67 & 4 & 13,33 & 8 & 2 & 14 & 46,67 & $<0,0$ \\
\hline Tống & 2 & 6,67 & 6 & 20 & 22 & 73,33 & 30 & 100 & \\
\hline
\end{tabular}

Nhóm bệnh nhân có độ tuổi < 50 có khả năng đạt kết quả điêuu trị tốt hơn so với nhóm có độ tuổi $\geq 50$. Mối liên quan này có ý nghĩa thống kê $\mathrm{p}<0,05$.

Bảng 5. Thời gian bi bệnh

\begin{tabular}{|c|c|c|c|c|c|c|c|c|c|}
\hline Kết quà & & Kém & & Khá & & Tốt & & Tống & \\
\hline Thời gian & $\mathbf{n}$ & Tỷ lệ (\%) & $\mathbf{n}$ & Tỷ lệ (\%) & n & Tỷ lệ (\%) & $\mathbf{n}$ & Tý lệ (\%) & $\mathbf{p}$ \\
\hline <3tháng & 0 & $\Omega$ & 2 & 6,67 & 14 & 46,67 & 16 & 53,33 & \\
\hline 23tháng & 2 & 6,67 & 4 & 13,33 & 8 & 26,67 & 14 & 46,67 & -0 \\
\hline Tống & 2 & 6,67 & 6 & 20 & 22 & 73,34 & 30 & 100 & 0,0 \\
\hline
\end{tabular}

Nhóm bệnh nhân có thời gian mắc bệnh $<3$ tháng cho kết quả điều trị tốt hơn nhóm bệnh nhân có thời gian mắc bệnh $\geq 3$ tháng. Mối liên quan này có ý nghĩa thống kê với $p<0,05$.

\section{BÀN LUẬN}

\section{1. Đặc điểm bệnh nhân nghiên cứu}

Về giới tính: Theo nghiên cứu của chúng tôi, tỷ lệ bệnh nhân nữ là $70 \%$, tỷ lệ bệnh nhân nam là $30 \%$. Kết quả này cũng tương tự với kết quả của Nguyễn Phương Lan với tỷ lệ bệnh nhân nữ là $66 \%$, nam $34 \%[3]$. Theo nghiên cứu của Chung Khánh Bằng[4] thì tỷ lệ mắc bệnh giữa nam và nữ là tương đương. Theo chúng tôi sự khác biệt này có lẽ do mẫu nghiên cứu còn quá nhỏ so với một điều tra dịch tê̂, cho nên sự phân bố này chưa phản ảnh được tình hình chung về giới tính với các bệnh nhân có hội chứng vai tay. Mặt khác, khi mắc bệnh phụ nữ thường chọn phương pháp điều trị bằng châm cứu nhiều hơn.

Về tuổi: Kết quả nghiên cứu cho thấy hầu hết các bệnh nhân hội chứng vai - tay có độ tuổi từ 40 đến 60 chiếm $70 \%$, tiếp đến độ tuổi trên 60 chiếm 16,67\%, độ tuối dưới 40 chiếm 13,33\%. Như vậy kết quả nghiên cứu của chúng tôi phù hợp với Nguyễn Thị Lực phần lớn bệnh nhân mắc bệnh ở tuổi trên 40 (chiếm 89,5\%), trong đó số người trên 50 tuổi (chiếm 62,7\%); Lê Hoài Anh thây tuổi từ 41 đến 50 chiếm tỷ lệ cao nhất 
$50,5 \%$ [5].

Về nghề nghiêp: Trong 30 bệnh nhân nghiên cứu, số bệnh nhân có nghề nghiệp lao động chân tay chiếm tỷ lệ cao nhất (60\%), tiếp đến số bệnh nhân lao động trí óc có chiếm tỷ lệ $26,67 \%$. Còn lại số bệnh nhân có nghề nghiệp khác chiếm tỷ lệ $13,33 \%$. Kết quả nghiên cứu này cũng phù hợp với Dương Tuấn Dũng [2], số bệnh nhân có nghề nghiệp lao động chân tay chiếm 75,5\%, nghề nghiệp khác có 24,5\%.

\subsection{Kết quả điêu trị lâm sàng}

Kết quả nghiên cứu cho thấy sau 7 ngày điều trị bệnh nhân không đau chiếm $50 \%$, có $6,67 \%$ số bệnh nhân đau ít và $23,33 \%$ số bệnh nhân đau vừa và $16,67 \%$ số bệnh nhân đau nhiều, 3,33\% số bệnh nhân rất đau. Sự khác biệt có ý nghĩa thống kê $p<0,05$. Sau 14 ngày điều trị bệnh nhân không đau chiếm $86,67 \%$, có $0 \%$ số bệnh nhân đau ít và $10 \%$ số bệnh nhân đau vừa và 3,33\% số bệnh nhân đau nhiêu, không còn số bệnh nhân rất đau. Sự khác biệt có ý nghĩa thống kê $p<0,05$. Theo $y$ học cổ truyền hội chứng vai - tay thuộc chứng thống tý nguyên nhân do phong hàn thấp. Khi cơ thể mệt mỏi, dương khí suy yếu, vệ khí không đầy đủ, tấu lý sơ hở. các tà khí thừa cơ xâm nhập vào bì phu, kinh lạc dẫn tới sự vận hành của khí huyết bị bế tắc ngưng trệ gây nền đau và hạn chế vận động "bất thông tắc thống". Do đó phép chữa chủ yếu là khu phong trừ thấp, thông kinh hoạt lạc, bổ dưỡng can thận để khí huyết được lưu thông, dương khí đây đủ và đuổi được tà khí ra ngoài. Người ta cho rằng có lẽ châm cứu có tác dụng giảm đau là do sự kết hợp của cả hai cơ chễ: đó là sự ức chế dẫn truyền cảm giác đau của tín hiệu xúc giác và sự hoạt hoá hệ thống giảm đau của cơ thể, dẫn tới bài tiết của các opiat nội sinh.

Theo bảng 3, sau đợt điều trị ta thấy mức độ khá và tốt chiếm tỷ lệ lần lượt là $73,33 \%$ và $20 \%$, mức độ kém chiếm tỷ lẹ là $6,67 \%$. Kết quả nghiên cứu của chúng tôi phù hợp với nhận xét của tác giả Lê Hoài Anh [5] cho thấy tác dụng của điện châm nói riêng, XBBH, vật lý kết hợp vận động trị liệu là những phương pháp không dùng thuốc có tác dụng tốt tới điêu trị hội chứng cổ - vai - tay do THĐSC vừa hiệu quả, an toàn, thuận tiện, không tốn kém có tác dụng giảm đau nhanh, tâm lý bệnh nhân thoải mái mang lại chất lượng cuộc sống cho bệnh nhân.

\subsection{Một số yếu tố liên quan đến kết quả} điêuu trị

Tuổi bi bệnh: Kết quả ở bảng 4 cho thấy nhóm bệnh nhân có độ tuổi $<50$ tuổi cho kết quả phục hồi tốt và khá cao hơn so với nhóm bệnh nhân có độ tuổi $\geq 50$, mối liên quan này có ý nghĩa thống kê với $p<0,05$. Bệnh nhân có độ tuổi càng trẻ kết quả phục hồi càng tốt có lẽ do khả năng hoạt động của hệ cơ, xương khớp, phản xạ thần kinh, thể lực còn tốt. Còn những bệnh nhân có độ tuổi càng cao thì khả năng phục hồi kém hớn so với người trẻ tuổi vì tuổi càng cao khả năng bù trừ của hệ tuần hoàn, phản xạ thần kinh và vận động của hệ cơ, xương khớp giảm sút so với người trẻ. Kết quả này phù hợp với nghiên cứu của Nguyễn Thị Phương Lan [3].

Thời gian bi bệnh: Qua bảng 5, nhóm bệnh nhân có thời gian mắc bệnh < 3 tháng $(53,33 \%)$ cho kết quả điều trị tốt hơn nhóm bênh nhân có thời gian mắc bệnh $\geq 3$ tháng $(46,67 \%)$, mối liên quan này có ý nghĩa thống kê với $p<0,05$. Nguyễn Thị Phương Lan[3] và nhiều tác giả khác đã nhận định rằng những bệnh nhân đến điêu trị càng sớm thì kết quả điều trị càng cao.

\section{KẾT LUÂ̂N}

Qua nghiên cứu tác dụng của điện châm, xoa bóp bấm huyệt trên 30 bệnh nhân có hội chứng cổ - vai - tay do thoái hóa đốt sống cổ, chúng tôi rút ra kết luận sau:

- Điện chầm kết hợp xoa bóp bấm huyệt có tác dụng giảm đau và phục hồi chức năng vận động trên bệnh nhân có hội chứng cổ - vai - tay do thoái hóa đốt sống cổ với 73,33\% tốt, $20 \%$ khá, $6,67 \%$ kém.

- Môt số yếu tố liên quan đến kết quả điều trị: Tuổi bệnh nhân < 50 cho kết quả điều trị tốt hơn so với nhóm bệnh nhân $\geq 50$ tuổi $(p<$ 0,05 ). Thời gian mắc bệnh $\leq 3$ tháng cho kết quả điều trị tốt hơn những bệnh nhân mắc bệnh $>3$ tháng.

\section{TÀI LIẸU THAM KHẢO}

1. Trân Ngọc Ân (2012) "Bệnh thấp khớp", Nhà xuất bản Y học, $\operatorname{Tr} 253-281$.

2. Dương Tấn Dũng (2006) "Điều trị đau vai gáy bằng châm cứu và xoa bóp", Tạp chí châm cứu Việt Nam số 23, Tr 21-22.

3. Nguyễn Phương Lan (2013) "Nghiên cứu tác dụng điện châm trong điều trị hội chứng vai tay", Luận văn Thạc sỹ Y học trường Đại học Y hà Nội.

4. Chung Khánh Bằng. (2012) "Nghiên cứu tác dụng phương pháp Tân châm trong điều tri viêm quanh khớp vai", Luận án Thạc sỹ $Y$ học Trường Đại học Y Hà Nội.

5. Lể Hoài Anh (2009) "Nghiên cứu ứng dụng phương pháp châm cứu bấm huyệt phối hợp vật lý trị liệu trong điều trị viêm quanh khớp vai", Tạp trí Châm cứu Việt Nam số 32, Tr 19- 21. 